\title{
A Study on Implication of Prototype Theory in English Vocabulary Teaching
}

\author{
Hongmei Zhang \\ Foreign Languages College, Inner Mongolia University, Hohhot, 010021, China
}

\begin{abstract}
Nowadays, English plays an increasingly important role in international communication. Vocabulary plays the important role in the process of English learning and teaching. Although the significance of the vocabulary teaching and learning have been noticed by the teachers and students, the current situation of English vocabulary teaching and learning is not satisfactory in most Chinese schools. This paper applies the prototype theory and other related theories, which contains the three levels of categorization and two cognitive mechanism, to vocabulary teaching and learning. The paper aims at exploring the implications that prototype theory indicates in English vocabulary teaching and learning, finding out the crux of English vocabulary teaching and learning. Teachers need to consciously foster students' metaphorical and metonymical awareness when teaching vocabulary.
\end{abstract}

Index Terms-prototype theory, vocabulary teaching, basic level terms, metaphorical and metonymical awareness

\section{INTRODUCTION}

The increasingly fast integration and expansion of global communication have been enhancing the lasting popularity of English. English vocabulary, which is the "building block" of this global language and carrier by which we express our thoughts and convey meanings, hence plays a particularly significant role in language teaching. Although we are aware of this significance, the long-standing problem in vocabulary teaching and learning is still there in China to be solved. Each Chinese four-year college graduate has spent an average of 12 years in learning English but they still have great difficulty in communicating in English. Their English vocabulary is seemingly enlarging, but actually still stuck in the basic level. This paper attempts to apply the prototype theory to English vocabulary teaching and learning in order to obtain valuable implications from it to find out the crux of English vocabulary teaching. The paper consists of five parts. The first part is an introduction to the background and the goal of this study. The second part is an overview of the studies on English vocabulary teaching and learning abroad and at home. The third part is the theoretical framework which mainly introduces the characteristics of prototype theory, the three levels of categorization and the two cognitive mechanisms. The fourth part is the implication of these theories for English vocabulary teaching and learning. The fifth part is the conclusion which summarizes this paper.

\section{LITERATURE REVIEW}

Before 1970s, language teaching emphasizing on grammatical structures rather than vocabulary. The research of vocabulary teaching and learning has been centered on in 1970s with the emergence of communicative approach, when researchers pay more attention to communicative proficiency and the meaning of vocabulary. Wilkins (1972) states that without grammar little can be conveyed, without vocabulary nothing can be conveyed. It shows that vocabulary is regarded as the most important part of a language. Rivers (1977) proposes that teachers should help the students master the communicative meaning of words. The revival of the appropriate vocabulary status leads plenty of researches on vocabulary from different aspects, and researchers also point out some vocabulary teaching and learning methods. Most of them agree that in order to learn vocabulary, learners should know the inner meanings of vocabulary and their antonym, synonym and homophone.

From the 1980s, researches on vocabulary teaching and learning have come into blossom with the appearance of the natural approach. There have been many writings on vocabulary research. Some researchers, such as Nattinger (1992), claims that phrases should be taught and learned instead of the individual words alone. Some researchers, such as Krashen (1990), think that memorizing words through reading is a better way for reading in a relaxing situation. Some researchers, such as Wallace (1982) and MaCarthy (1990), suggest that vocabulary should be taught and remembered in a meaningful context. Some researchers and teachers in Britain designed a lot of exercises, which were based on semantics theory, to help students master the usage of common and high-frequency vocabulary, and one of them divides the vocabulary teaching into the implicit teaching, which is to recognize clues in context, use monolingual dictionaries and avoid defining words with their bilingual equivalents, and explicit teaching. Still there are some other researchers, such as Oxford (1990) says that not all students benefit equally from vocabulary learning techniques and that different techniques may be appropriate to different students, and he recognizes four vocabulary learning strategies, that is, memory strategy, social strategy, metacognitive strategy and cognitive strategy. 
Since the 1990s, researchers have studied on vocabulary teaching and learning by using the latest research findings of linguistics, and some new vocabulary teaching methods have come into being in the past twenty years, such as lexical approach, incidental learning, mental lexicon and cognitive-theory-guided method. Lexical approach, put forward by Lewis (1993) who says "language is grammatical lexis, not lexicalized grammar", is an approach against grammar-based approaches to foreign language teaching. Incidental learning, which is to learn new words incidentally through reading articles or listening to songs, is against intentional learning, which is to learn new words intentionally by repeating the words list or by doing exercises. Mental lexicon is the word in permanent memory, and there are two important aspects of vocabulary learning, namely, the way vocabulary is presented and how vocabulary is stored and organized in the mind as the mental lexicon and how mental lexicon can be retrieved. Some researchers integrate cognitive linguistics with the language teaching and learning, and some preliminary research results emerge. For example, Mouton (2003) explains the structure of words including typical structure, family resemblance structure and radiated structure, and explains the relations among the several meanings of a polysemous word by using metaphor, metonymy, image schema and association. Csabi 92008) explains the motivation among the different meanings of polysemous words. Studies abroad contribute a lot to studies at home.

In China, for a long time, English teaching and learning has been focused on grammar and structure while the vocabulary teaching and learning have been undervalued, and English vocabulary teaching and learning methods have been influenced by some west methods such as the grammar translation method, the audio-lingual method, the communicative approach. Although researches which have studies on vocabulary teaching and learning at home is much later than those researches abroad, some progress has been achieved. There are many articles and works about vocabulary teaching and learning, and some researches employ linguistics theory on vocabulary learning and teaching. The following will illustrate some typical examples.

Zhao Rui (2001) states two vocabulary learning and teaching methods. One is to teach vocabulary by using computers for the computers can show vivid pictures which can draw learners' attention. The other one is to teach word formation. For example, when "triangle" is taught, teachers first teach the prefix "tri-", and then the following prefixes about number, "mono-", "bi-", "penta-", and "multi-", etc. In this way, students can learn many words. Meng Lijuan (2001) claims that to distinguish passive words form active words is important because the techniques of active words learning include problem-solving, role-playing and brief writing to cover the selected items while the techniques of passive words learning include consulting dictionary for meaning and doing extensive reading comprehension. Zhu Yafu claims that vocabulary teaching and learning should be associated with cultural background of vocabulary.

Peng Jianwu researches the relationship between connectionism and vocabulary teaching, which assumes that lexical information is stored in networks of nodes and the process of creating the relationship between its form and meaning happens when neural networks are strengthened over time with the learner frequently encountering the item in the input. Thus, teachers should provide students with adequate English comprehensive input. Qu Dianning (2010) claim that the application of corpus is important to the vocabulary teaching and learning. Liang Xiaobo (2002) studies the application of cognitive linguistics to English vocabulary teaching and learning, and he says this application can attach importance to the aspects such as the semantic motivation of terms, the underlying link between the polysemy of terms and the theory of cognitive semantics.

From the above review, we know that vocabulary teaching and learning have been studied by many researchers abroad and at home. These researches, especially the ones which apply linguistics theories, instruct a lot in vocabulary teaching and learning for teachers and students. However, only a few of them discuss vocabulary teaching and learning from prototype theory, and in spite of the fact that there are plenty of researches on English vocabulary, teachers and learners still have lots of problems. Therefore, to reduce the burden of teachers and students in vocabulary, this thesis tries to apply prototype theory to English vocabulary teaching and learning with the help of previous research results.

\section{THEORETICAL FRAMEWORK}

\section{A. Prototype Theory}

Rosch (1976) proposes the prototype theory through a series of experiments. A prototype is considered to be the concrete typical instance of its class defined operationally by people's judgments of goodness of membership in the category, which has more common features than other members of this class, or a prototype is the abstract schematic representation or attribute collection. The prototype theory suggests that many mental concepts we have are really prototypes, and people often do classify things or define a concept by reference to what they regard as being typical instances for prototype is the first member that comes into people's mind when referring to a particular category. For example, a prototype of the category of bird would be more like a small bird which flies than a large flightless bird like an emu.

The following are some basic ideas of the prototype theory. First, the members of a category are formed around prototypes rather than a set of necessary and sufficient features, and the members are overlapping and share a part of common features. Second, there are not any set of attributes belonging to all members, yet each member has at least one attribute in common with some other members of the category, and some members share more attributes than others, so some members of a category are more central while others are on the edge, and degrees of typicality and continuous variables can be presented. Because the prototype of the category has the largest features, it is the best example of the 
category. Third, category has fuzzy boundaries, which means that neighboring categories have no clear-cut boundaries and peripheral members can be usually classified into another category. Therefore, typical members can be identified easily while non-typical members are difficult to be classified for they have less common features and may have some common features with members of other categories. Fourth, the membership of a category and prototypes are different in different people's minds, which are not fixed and may change as the context and the social and cultural knowledge change. Thus, due to different contexts or cultural backgrounds, different countries take different attitudes towards prototypes of a category. In addition, prototypes of a category are different for people living in different periods.

\section{B. Three Levels of Categorization}

We are surrounded by identifiable organisms and concrete objects. When the need comes to categorize three things, we will normally have a choice between categories on different levels of generality: basic level, superordinate level and subordinate level. The informativeness reflected by each level is different. The basic-level category, relying on human beings' basic perception, is not too abstract and too concrete, and offers the largest amount of relevant information concerning the objects and organisms of the world, so it is where the largest amount of relevant information about a thing can be obtained. Lakoff (1987) states that the basic level category has the prototypical characteristics, so it is most commonly used to refer to members of a category. Superordinate categories, which are above basic-level categories, are more abstract and more general. While subordinate categories, which are below basic-level categories, are more concrete and more specific. For example, bird is regarded as a basic level category, the category of animal as superordinate to it, and the category of sparrow as subordinate to it.

The following are the summary of characteristics of the three level categories. First, the basic level categories have the common gestalt, a large number of category-wide attributes, the prototype structure, the natural access to the world, and linguistic forms are short and mono-morphemic words. Second, the superordinate level categories have no common gestalt, one or very few category-wide attributes and the salient general attributes, the family resemblance structure, the highlighting and collecting function, and linguistic forms are often longer and morphologically complex words. Third, the subordinate level categories have almost the identical gestalt, a large number of category-wide attributes and the salient specific attributes, the high degree of homogeneity among category members, the specifying function, and linguistic forms are often morphologically complex words.

\section{Two Cognitive Mechanisms}

Traditionally, metaphors and metonymies have been interpreted as figures of speech. In fact, human conceptual systems are pervasively structured by metaphor and metonymy, which are powerful cognitive tools for human beings' conceptualization of abstract categories.

\section{Metaphor}

Lakoff and Johnson (1980) hold that metaphor is not just a way of traditional view of expressing ideas recurring to language, but a way of thinking about things, which can be divided into the following types.

The first type is structural metaphor which is the case where one concept is metaphorically structured in terms of another (Lakoff $\boldsymbol{\&}$ Johnson, 1980). The function of this type is to enable people to understand target A resorting to the structure of source B. For example, "I hit back at his criticism" and "I have never won on argument with him" are two sentences which are all structured by the conceptual metaphor "ARGUMENT IS WAR". People usually structure an unfamiliar concept or target domain (argument) by using highly structured and familiar concept or source domain (war). The second type is orientational metaphor which organizes a whole system of concepts with respect to one another. It is easy for people to express abstract concepts, like emotion or healthy states, via the concrete spatial concepts. For example, "I am feeling down" and " my spirits rose" are sentences which use the "up-down" orientational metaphor to express the meaning of "HAPPY IS UP; SAD IS DOWN". The third type is ontological metaphor which refers to ways of viewing events, activities, emotions, ideas, etc., as entities and substances. People can categorize events, actions and states as substances. For example, "we need to combat inflation" is structured by conceptual metaphor " INFLATION IS AN ENEMY". Ontological metaphors contain entity metaphor, container metaphor, and personification, and container metaphor is the most prototypical one. For example, "they are out of trouble"is structured by conceptual metaphor "TROUBLE AS CONTAINER".

\section{Metonymy}

Lakoff and Johnson (1980) states that apart from metaphor, metonymy is a related conceptual mechanism central to human thought and language, which is using one entity to stand for another. Metonymies are represented as "B stands for A", where "B" is the vehicle while " $A$ " is the target. For example, in the sentence "the ham sandwich has wandering hands", the target is the customer while the vehicle is the ham sandwich.

Both metaphor and metonymy are based on people's experience and they make the categorization concrete.

\section{IMPLICATION FOR VOCABULARY TEACHING}

\section{A. Value of Prototypical Meaning in Vocabulary Teaching}

Xiao Fushou (2003) claims that when design vocabulary teaching project, we can use prototype theory as reference point. Not every member is equally representative of a category, and there are prototypical members and the others are 
less typical. Prototypical members of the category have the largest number of attributes in common with other members, which is to say that prototypical members are better examples and should deserve much attention than those non-prototypes. The characteristics discussed previously can be applied in vocabulary teaching and learning.

Evelyn and Cheryl (2001) claims that in a semantic category, items are not equal and arranged by prototypes. According to prototype theory, one of these lexical items should be more central and can represent the given semantic category, which is called the prototypical meaning, while the other peripheral members can be extended upon the prototypical items, so all the meanings will form a meaning chain. The prototypical meaning is familiar to language users.

Take the word "head" as an example. First, in sentence "the head of the tiger was hit by Wu Song", "head" means part of the body, which is the prototypical meaning of head and this meaning can also be considered as the easiest and first learned meaning. Second, in sentence "the cold man holds the head of the walking stick tightly", "head" refers to things like a head in form, in which the prototypical meaning is almost lost. Third, in sentence "the heads of the delegation attended the 2006 China Africa Forum", "head" means the chief person of an organization, in which the meaning becomes quite far away from the prototypical meaning and more abstract. Fourth, in sentence "use your heads", heads means intelligence, which is extended by metaphor. From the above examples, we know that on the basis of a word's prototypical meaning, the word gets its metaphorical and metonymic meaning gradually, which shows the concrete meaning of the word becomes the abstract one in different language contexts.

Most words have many meanings, and these meanings are related to each other in a certain degree. The prototypical meaning comes into being at the earliest time, and it is also the first meaning to be learned by language community members. The prototypical meaning of a word is more easily mastered by the learners while other meanings that are marginal are not so easy to be mastered. Therefore, teachers should teach the prototypical meaning of a word first and attach important to the explanation of prototypical meaning, and also explain the relations between prototypical meaning and derived meanings to help students get better understanding of the words. If students get the prototypical meaning of a word, they will find it easier to learn and deduce other meanings.

\section{B. Implications of Three Levels of Terms for Vocabulary Teaching}

The following will suggest some implication of the three levels of terms for vocabulary teaching and learning, which includes: giving priority to basic level terms and paying attention to superordinate and subordinate terms.

Wang Ying (2009) states that basic-level categories, which share a variety of properties with one another, is the most basic starting point for people to understand the world and it is the most powerful tool for people to categorize the world. The basic level is the level first named and understood by children, and the words are simple but useful, thus learning vocabulary is better to begin from the basic level vocabulary to the non-basic level vocabulary. To be more specific, the priority should be given to teach the basic level terms due to the following aspects.

First, most of the basic level terms are simple and short, so they are easier acquired and used by students. Second, basic level category processes the most attributions and common gestalt features so that terms at this level have more close relation with the concrete objects, which can help students easily remember them. Third, the basic level terms are frequently used in the daily communication, so they can be memorized for a long term by students. Fourth, the basic level terms have a strong ability of word-formation potential and many subordinate level terms comes from the basic level terms, and based on this, students can learn vocabulary from the higher and lower levels of vocabulary. Therefore, teachers should assign basic-level terms to the primary place.

The priority of basic-level category terms does not mean that other categories should be ignored in language teaching. The superordinate level terms should be always introduced together with basic level terms which can help students understand and remember them all. For example, when introducing the basic level terms like "chairs", "tables" and "bed", their higher level term "FURNITURE" should be introduced at the same time. Different from superordinate categories, attributes of subordinate categories are specific which can help students master the words always used in some specific fields.

Teachers should appropriately link the superordinate, subordinate and basic-level terms together, which may help students enlarge their English vocabulary. Students can make a list in their notebook of each category which is beneficial for their long-term study.

Metaphor, which is based on the similarity and association, uses one thing to refer to other things, and then it produces a new different but similar meaning based on the old meaning of the word. According to the features of metaphor, students should use the metaphorical meanings of words to expend the depth and breadth of their vocabulary. First, the metaphor can help students understand vocabulary well. For example, in sentence "we also make choices based on how the products are grown or made: environmentally friendly food, or 'eco-food', is produced by companies who have tried to use green and clean ways to grow it", here "green", which has a different meaning from the traditional meaning as "one kind of color", means "environmentally friendly". Both of the two meanings have the features as: healthy, clean, and environmental, so it can make use of the association and similarity of metaphor to teach the new meaning of the same word, which can be easy for the understanding of students. Second, metaphor is helpful for students' understanding of preposition. For example, I am feeling up. Third, it is useful to remember the words in groups based on metaphor. For example, the teacher can summarize some metaphors to explain the verbs describing the economic indicators, such as "economy is an airplane" "economy is a kind of diving" or "economy is a kind of 
mountain climbing", which can help students to remember words in these examples.

Metonymy gives inspiration to teaching English as well as metaphor. For example, "board" can refer to the table and can also refer to the people sit around the table. Because of metonymy, words get different meanings as well, and the integration of metaphorically motivated language into vocabulary teaching and learning can expand students' vocabulary.

\section{CONCLUSION}

This paper adopts prototype theory to English vocabulary teaching and learning. From what have been discussed, we see that prototype theory has great utility to promote vocabulary teaching and learning. The followings are the main points of this paper. First, from the prototype theory, we can get the implication that the prototypical meaning should be taught before the other meanings. Second, teachers must pay more attention to the teaching of basic level vocabulary because the basic level terms have a strong ability of word-formation potential. At the same time, teachers should also consciously focus on the superordinate and subordinate level vocabulary, which is beneficial for students to learn vocabulary in different categories. Third, teachers should cultivate students' metaphorical thoughts and then lead them to regard metaphor and metonymy as cognitive tools to learn vocabulary.

Without doubt, this paper is not comprehensive. For example, it must be noticed that the learning of basic level terms is more effective for the elementary stage students, but it is not enough for a second learner for the language output, so the emphasis of basic level terms can not be extreme. This paper can not reach that far unfortunately, and it needs research further.

\section{REFERENCES}

[1] Csabi, S. (2008). Cognitive Linguistic View of Polysemy in English and ItImplications of Teaching. In P. Robinson \& N. C. Ellis (eds), Handbooks of Cognitive Linguistics and Second Language Acquisition. New York: Routledge.

[2] Evelyn, H \& B. Cheryl. (2001). Vocabulary, Semantics and Language Education. Cambridge: Cambridge University Press.

[3] Krashen, S. D. (1989). We Acquire Vocabulary and Spelling by Reading: Additional Evidence for the Input Hypothesis. Modern Language Journal, 73: 440-462.

[4] Lakoff, G. (1987). Women, Fire, and Dangerous Things: What Categories Reveal about the Mind. Chicago: University of Chicago Press.

[5] Lakoff, G \& M. Johnson. (1980). Metaphors We Live By. Chicago: University of Chicago Press.

[6] Lewis, M. (1993). The Lexical Approach: The State of ELT and a Way Forward. Hove: Language Teaching Publications.

[7] Liang Xiaobo. (2002). Implications of Cognitive Linguistics for English Vocabulary Teaching. Foreign languages and Their Teaching, 2: 35-39.

[8] McCarthy, M. J. (1990). Vocabulary. Oxford: Oxford University Press.

[9] Meng Lijuan. (2001). On Cultural Leading-in in English Vocabulary Teaching. Journal of Liaoning Business Vocational College, 4: 65-66.

[10] Mouton, G. (2003). Cognitive Approach to Lexical Semantics. Berlin: Mouton de Gruyter.

[11] Nattinger, J. \& J. DeCarrico. (1992). Lexical Phrases and Language Teaching. Oxford: Oxford University Press.

[12] Peng Jianwu. (2002). On the Application of Connectionism to English Vocabulary Teaching. Foreign Language World, 4: 45-50.

[13] Qu Dianding. (2010). On Language Chunk Acquisition Based on Corpus. Foreign Language World, 1: 47-53.

[14] Rivers, W. M. \& M. S. Temperley. (1977). Building and Maintaining an Adequate Vocabulary. English Teaching Forum, 15: 2-7.

[15] Rosch, F. (1976). Classification of Real-word Objects: Origins and Representations in Cognition. In S. Ehrlich and E. Tulving (eds), La Memoire Semantique. Paris: Bulletin de Psychologie.

[16] Wallace, M. J. (1982). Teaching Vocabulary. London: Heinemann Educational Books.

[17] Wang Ying. (2009). Cognitive Linguistics. Shanghai: Shanghai Foreign Language Education Press.

[18] Willkins, D. A. (1972). Linguistics in Language Teaching. London: Edward Arnold.

[19] Xiao Fushou. (2000). On Teaching English Vocabulary with Word-forming Method. Foreign languages and Their Teaching, 5: 34-36.

[20] Xiong Xueliang. (2003). New interpretation of Linguistics. Shanghai: Fudan University Press.

[21] Zhao Rui. (2001). On Vocabulary Teaching of College English. Journal of Shaanxi Normal University, 2: 343-346.

[22] Zhu Yafu. (2005). Seven Types of Meanings and English Vocabulary Teaching. Foreign languages and Their Teaching, 9: 28-35.

Hongmei Zhang (1975- ), female, MA of Linguistics Abroad and Applied Linguistics, Inner Mongolia University, 2008. She is currently a lecturer and she has been teaching College English since 1997. She is interested in teaching methodology and Literature, especially in American modern theater and she ever did research on this field in the United States through the years of 2007 and 2008. She has published a number of articles on literature and English teaching. 